\title{
Research on Methods of Improving the Teaching Quality of Liberal Arts Students in Electrical and Electronics Courses under the New Engineering Course
}

\author{
Panfeng Guo \\ School of Electrical and Energy \\ China Three Gorges University \\ Yichang, China \\ 296472604@qq.com
}

\author{
Xin $\mathrm{Li}^{*}$ \\ School of Electrical and Energy \\ China Three Gorges University \\ Yichang, China \\ 397038289@qq.com
}

\author{
Jiangzhou Cheng \\ School of Electrical and Energy \\ China Three Gorges University \\ Yichang, China \\ 1366877334@qq.com
}

\begin{abstract}
Since the introduction of the "new engineering" in 2016, it has a great impact on the teaching and learning in colleges and universities. It is proposed that education and teaching should be intercrossed with science, humanities and engineering. Universities should cultivate compound and comprehensive talents. The discipline of electrician and electronics has its special status and characteristics as a basic subject of non-e lectrical enginee ring in higher education. Starting from the characteristics of electrical and electronics courses, this paper analyzes and discusses the causes of the difficulties in teaching from the psychology of students, the way of thinking, the syllabus and so on. On this basis, according to the background of "new engineering", we tailor the te aching syllabus for liberal arts students. Some suggestions are put forward to improve the teaching quality of the electrical and electronics courses of liberal arts students, in connection with the reality of life, the practice of enterprise engineering, the increase of positive energy and the diversification of teaching methods.
\end{abstract}

Keywords-new engineering; electrical and electronic course; teaching quality; learning method

\section{INTRODUCTION}

In February 2016, Fudan University held a seminar on strategic development of university engineering education. At the seminar, the research and practice of "New Engineering" was officially put on the charter. Under the background of "three new" (new technologies, new forms of business, and new industries), higher requirements have been placed on the ability of engineering talents to innovate and start up.Zhang Daliang, Director of the Higher Education Department of the Ministry of Education, put forward a request for support for new engineering talents. At this point, the concept of "New Engineering" was proposed. Tianjin University, Dongguan
University of Technology, etc. carried out the "New Engineering" personnel training model reform. The characteristics of "New Engineering" talents are the intersection and integration of disciplines. The "New Engineering" is a new viewpoint put forward from the perspective of comprehensively innovating China's higher engineering education in the new era to adapt to lead the new economic development strategy. The school where the writer is located conforms to the development and has made corresponding innovation education and passed the professional certification quality assessment. The characteristics of electrical and electronic technology itself, including both circuit and electronic technology basic courses, its special status is self-evident. Especially in the context of interdisciplinary integration, colleges and universities in order to better serve the community and improve the employability of students, many colleges and universities in the design of professional, often take into account the needs of the social industry and the characteristics of the school to adapt to employment Requirements, and then put their own professional infinity near the hot professional or specialty. For example, in recent years, the electric power industry has become a popular and relatively good job. Therefore, many colleges and universities will change some majors to electricity and even some liberal arts majors in order to recruit students or adapt to student employment requirements. For example, the marketing major should be a liberal arts major and the students are all liberal arts students. However, when the direction is divided, the characteristics of the school (power characteristics) will be taken into consideration, and the marketing specialty will be changed to "marketing power direction". In this way, students are bound to learn professional basic courses on electricity. If we still follow the method of teaching students, it is clear that 
we will not be able to adapt the liberal arts students to the basic course of electricity. This article will take the liberal arts students studying "electrical and electronics" as an example, combine the needs of "new engineering", discuss how to teach, and improve the learning efficiency and quality of liberal arts students.

\section{THE STATUS QUO OF THE TEACHING OF ELECTRICAL AND} ELECTRONIC COURSES

\section{A. Characteristics of Electrical and Electronic Courses}

On the one hand, the content is numerous and wide. Electrotechnics is a basic course for non-electrical majors. It includes circuit theory modules, digital circuits and analog circuits, as well as five practical contents. The content is more specific to the students' comprehensive ability requirements, and the compression of academic hours is often Teaching limits, for liberal arts students must pay attention to quality but also to grasp the time, so that students think about the theory and methods need further reflection.

On the other hand, electrical and electronic theory is very strong. The content of this course is deepened. The study of the circuit theory of the first module is the basis of the second module analog electronics, while the digital part is the training of logical thinking. The circuit theory module focuses on the mastery of basic theory and basic methods, including reference direction, power conversion, Kirchhoff theorem, Thevenin theorem, and so on. The theory is strong; the analog electronic part focuses on the role of the device and the analysis of the circuit. Including the theory of strong triode amplification principle, as well as the theory of differential equivalence, etc.; digital part of the emphasis on logical thinking ... As the three parts of electrical and electronics, the theory is relatively strong.

\section{B. Reasons for difficult electric and electronic teaching}

First of all, students have a fear and disgust psychology. Because of the large number of electrical and electronic materials, coupled with the fact that they are a liberal arts student for a long time without a physical basis, it is very difficult. When you see that the content of the first chapter is a circuit, there is a kind of psychological implied that you do not learn well and do not want to learn. After starting class, it is even more "a paste" when it comes to the reference direction, and then it is not interesting to learn later. In this way, we will also be very passive in the teaching process.

Secondly, the liberal arts engineering curriculum is not enough. It was the liberal arts that I chose. I didn't have much influence on these courses. From the learning process, some students think that they chose the "marketing" profession. Why do they need to understand the so-called "magnification of triodes"? Why do they need to calculate and design logic circuits? After questioning others, he then told himself that this course is not important and that learning does not matter.

In addition, the way of thinking is different. Strong theoretical, logical thinking. Most students who study liberal arts are more likely to jump in their thinking or to be more eclectic. However, most of the contents of circuit theory and electronic content are very fixed. It is necessary to think in a certain way to be able to solve and analyze. Therefore, the liberal arts and electronics courses required by liberal arts students need a certain method and method.

Finally, the syllabus was over-examination and improper teaching methods were chosen. The course of electrical engineering and electronics is often a course for non-electric engineering majors, so it belongs to science and engineering and has a certain foundation for mathematics, physics and thinking. The syllabus for teaching is often written in accordance with the requirements for the examination of science and engineering. However, with the rise of electricity, for example, liberal arts majors in the direction of marketing power have also begun to offer this course, and the corresponding syllabus has not been updated in a timely manner. There is bias in the emphasis. In addition, according to the usual teaching, we like to use the teaching methods and methods, these arts students are not used, so the method of teaching students in accordance with their aptitude, it seems very important at this time [2]. The vast majority of students like to have more hands-on or hands-on practice, discussion or self-study classroom teaching methods; a very small number of students prefer to teach in a teacher-oriented manner. Therefore, formulating effective syllabus and teaching methods is imminent.

\section{SOME SUGGESTIONS FOR IMPROVING TEACHING QUALITY}

\section{A. Tailored liberal arts student syllabus}

According to the "new content" and "new requirements", an effective syllabus needs to be established. Due to the content of the electrical and electronics courses, how to effectively complete the classroom teaching according to the characteristics of the students during the limited hours and ensure the quality has become our biggest test. Different teaching syllabuses for different teaching subjects can be repositioned to a certain extent. For the course of electrical and electronics, the requirements of the outline of the science and engineering disciplines from the chapters, from basic circuit concepts and basic theorems to analog-to-digital conversion are teaching requirements, and the examination requirements are based on basic circuit theory and analysis methods, electronic circuit amplification and Analysis, combinational logic circuit analysis and design are the key examination contents. However, for the course opened by liberal arts students, we must know the emphasis. The purpose of the first course is to give these liberal arts students and understanding of basic knowledge about "electricity" rather than to analyze and analyze certain circuits for examinations. Therefore, the outline must be tailored. For example, in this part of the analysis of transient circuits, engineering students are harder to learn. If students are hardened and liberal arts students talk about it, they will make them even more incomprehensible and lose their confidence and perseverance in class. In this case, teaching will be more effective. It is impossible to talk about it. When the outline is formulated, these factors must be taken into account. Those with a particularly strong theoretical basis and a large amount of calculation can be dealt with and changed slightly, mainly based on "quality education". 


\section{B. Contact with students to cultivate student interest}

Practice and interest are the biggest teachers. If you have the opportunity, you can let the students walk into the company, or go into the reality of life and understand the basic applications and innovative applications of the learned knowledge. According to the characteristics of the contents of the electrical and electronics courses, including the circuit theory part and the electronic part, these two contents are natural sciences that are closely related to life[3]. They are useful, interesting, and not difficult to learn. Therefore, in the teaching process, it is not necessary to emphasize calculations and analysis, but to connect with reality, to impose curiosity on students, and to cultivate their interests and common sense. This kind of teaching will be more effective and practical for students. Let them learn more motivation. For example, when we study the applications of associative and non-associative directions, the calculation and judgment of power is a key point. In the teaching process, we can explain some phenomena in ordinary life through some examples. Can explain why the same is a dry battery, some dry batteries are still absorbing power, charging the load. For example, in the teaching process of AC, we can also relate to the reality of life and explain the entire composition and use of bits and pieces to learn. In addition, the purpose of learning is to apply, after higher education is to serve the community better, so, in the classroom teaching of electrical and electronics, you can arrange several related basic experimental operations, students can visual circuit components, circuit principles and circuit laws, Electronic devices and applications, etc., to understand the relevance and differentiation of curriculum theory and practice. Teaching methods that do not deviate from real life may be more suitable for liberal arts students to study science courses.

\section{Timely dredge, introduce positive energy}

Humanistic care and communication are also essential in teaching. Regardless of how the outline of the electrical and electronics development programs, how to reduce the difficulty, the difficulty and focus of the course exist. Therefore, there are always some hard-to-understand difficulties and key points that will make students want to give up their studies. In the teaching process, observe the status of the students, plus the situation of the assignments, and communicate with the students in a timely manner so as to understand their difficulties. How to communicate is a learning that is worthy of consideration by each of our teachers. Stand in the student's perspective to communicate, encourage students, dilute difficult-tounderstand details, increase student confidence, and introduce positive energy.

\section{Properly introduce new teaching ideas and teaching methods}

The current teaching classroom is completely different from the previous one. The knowledge of learning is wide and wide. The student's demand for knowledge and the way to obtain knowledge are not only classrooms. Therefore, proper methods of changing the teaching methods may have effects. In particular, as a liberal arts student, his knowledge of the humanities and humanities can also be integrated into the electrical and electronics courses. For the liberal arts students to learn the content of engineering, students are interested in the process, not the calculation itself. In addition, the circuit electronic simulation software can be fully utilized to simulate the dynamic experiment diagram to represent the actual circuit experiment, which can not only increase the atmosphere of the course but also stimulate students' interest. In addition, in addition to using a combination of multimedia and board-based teaching, teachers can also use simulation software to create courseware such as CAI and FLASF. They can not only combine real-time simulation with the theoretical content of teaching in the teaching process, making teaching more profound and vivid. , also increase the interest of the course in the teaching process. In addition, "flipping classroom" is also a new type of teaching method and concept. For small class teaching, it can be carried out in a grouped form according to the "fragmented" teaching content and theme. In short, in teaching methods, we fully mobilize the enthusiasm of students to achieve a diversified teaching model and improve their creativity.

\section{CONCLUSION}

The emergence of new engineering disciplines is bound to challenge the education and teaching of various universities, especially for comprehensive and engineering colleges, it is even more challenged and reformed. In this context, this article has made corresponding reforms to the teaching of electrical and electronics. The following conclusions were drawn through the study: (1) According to the actual life and engineering experience, the teaching contents and syllabuses suitable for liberal arts students were formulated; (2) The classroom teaching methods could not be unified. To break the traditional teaching methods, you can try Software simulation teaching and "flipping classroom" forms a variety of teaching methods; (3) In this teaching process, human knowledge and communication can be integrated to improve students' confidence; (4) Appropriately increase the content of the practice part and cultivate Better creative talents that serve the society. In short, as long as the teaching reform of the Student Union Center will be rewarded.

\section{REFERENCES}

[1] Raud Z, Vodovozov V, Aksjonov A, "Promotion of the students' success in higher engineering education,” Power and Electrical Engineering of Riga Technical University (RTUCON), 2017 IEEE 58th International Scientific Conference on. IEEE, 2017, pp. 1-6.

[2] Zhang Z, Hansen C T, Andersen M A E, “Teaching power electronics with a design-oriented, project-based learning method at the Technical University of Denmark,” IEEE Transactions on Education, 2016, vol 59(1),pp. 32-38.

[3] Li Y, Wu Y, Liu X, "The teaching reform and exploration of national quality resource sharing course of electrical machinery,”/Electrical Machines and Systems (ICEMS), 2016 19th International Conference on. IEEE, 2016, pp. 1-4.

[4] Koroteyev, V. I., V. V. Florentsev, and N. I. Florentseva. "Educationalresearch laboratory "electric circuits" on the base of digital technologies." AIP Conference Proceedings. vol. pp. 131-141, August. 2017.

[5] Sun W, Guo B, Pan R, "Research on the Teaching of Linear Signal System Course Under the Guidance of Engineering Concept,” Teaching and Learning with Technology: Proceedings of the 2016 Global 
[7] Nikolic S, "Understanding how students use and appreciate online resources in the teaching laboratory," International Journal of Online Engineering, 2015, vol 11(4),pp. 8-13.

[8] Montenegro D, Hernandez M E, Ramos G A, “A realistic generator of power quality disturbances for practicing in courses of electrical engineering," Computer Applications in Engineering Education, 2015, vol 23(3),pp. 391-402. 